\title{
Enhanced Proliferation and Growth of Human Lung Epithelial Cells on Gelatin Microparticle Loaded with Ephedra Extracts
}

\author{
Dolly Singh, ${ }^{1,2}$ Deepti Singh,, ${ }^{1,2}$ Soon Mo Choi, ${ }^{1,2}$ and Sung Soo Han ${ }^{1,2}$ \\ ${ }^{1}$ Department of Nano, Medical \& Polymer Materials, College of Engineering, Yeungnam University, 280 Daehak-ro, \\ Gyeongsan, Gyeongsanbuk-do 712-749, Republic of Korea \\ ${ }^{2}$ YU-ECI Medical Research Center, Yeungnam University, 280 Daehak-ro, Gyeongsan, Gyeongsanbuk-do 712-749, Republic of Korea \\ Correspondence should be addressed to Sung Soo Han; sshan@yu.ac.kr
}

Received 23 August 2013; Revised 16 October 2013; Accepted 16 October 2013

Academic Editor: Zhongkui Hong

Copyright (C) 2013 Dolly Singh et al. This is an open access article distributed under the Creative Commons Attribution License, which permits unrestricted use, distribution, and reproduction in any medium, provided the original work is properly cited.

\begin{abstract}
The objective of this work was to evaluate the effect of extracts of Ephedra gerardiana loaded onto gelatin particles on human lung epithelial cells. Particles were synthesized using oil-water emulsification technique and were further stabilized by glutaraldehyde. Particle size was evaluated using SEM and zeta potential analyzer and was found to be in the range of $600 \mathrm{~nm}-1.32 \mu \mathrm{m}$. Drug release profile showed controlled and constant release of extract over the period of 5 days. In vitro biocompatibility of gelatin particles loaded with solvent-free extract of Ephedra gerardiana was tested with human lung epithelial cells. Gelatin particle acted not only as scaffold for cellular adhesion but also as carrier matrix for controlled release of extracts. The cell viability was significantly high when cultured in the presence of Ephedra extract in comparison to cells without Ephedra and 2D system as seen in MTT, SEM, and live/dead staining assay. It is concluded that gelatin microparticle functions both as drug delivery system and scaffold; however, the main finding was the effect of Ephedra extract on human lung cells resulting in enhanced proliferation and consequent promotion of ECM production indicating that extract could be a bioactive component that can be utilized in tissue engineering and regenerative medicine.
\end{abstract}

\section{Introduction}

Delivery of various growth factors and antimicrobial drugs is impetus in achieving tissue regeneration [1]. A wide range of drug carriers have been fabricated using natural and synthetic polymeric materials $[2-4]$ as these system offers advantage such as controlled release of drug and provides a high surface area which allows efficient drug loading and releasing from these polymeric matrix [5] along with attaining local site specific drug delivery [6]. For over a decade, particle-based delivery vehicles especially polymeric particles have been extensively evaluated as novel systems [7]. A porous particle provides larger surface area both for loading drugs as well as cell attachment and proliferation and also provides an easy passage for gaseous and nutrient exchange [8]. Choosing a polymer for the fabrication is as important as the drug or a bioactive molecule is loaded onto these matrices. Gelatin, a known hydrolyzed collagen, is extensively used in biomedical and food industries [7]. Effective release of bioactive growth factors or drugs is achieved by incorporating these potent and expensive compounds into microparticles, which offers control release at the site of injury. In case of highly biodegradable microparticles, the matrix itself is eroded as the bioactive agent is released, leaving no trace of the delivery system. Gelatin is often chosen in tissue engineering due to RGD motifs that act as cell binding receptors and is easily biodegradable in body simulating fluid undergoing hydrolytic cleavage [9]. Particles prepared using gelatin offer superior advantage as they are easily soluble in water thus making it simpler for the loading of bioactive compounds and drugs.

Ephedra gerardiana, an herbal plant, is ayurvedic medicine used for treating bronchitis and asthma along with various other lung related disorders. Traditionally it 
contains $50 \%$ ephedrine and the rest $50 \%$ is composed of other alkaloids like pseudoephedrine and so forth and it is consumed as herbal tea to relieve bronchitis and blood pressure [10].

Human lung cells are known to have limited capacity to regenerate and do not self-repair or regenerate beyond the cellular and microscopic level [11-13]. Lung development is affected by various air pollutants leading to significant increase in risk of lung disorder in one's life. Exposure to ever increasing air pollution directly affects the cases of previously existing respiratory disorders, increases the cases of asthma, and triggers the development of chronic diseases like lung cancer, emphysema, and so forth [14].

In this study, we have fabricated gelatin particles, loaded with solvent-free ethyl acetate extract of Ephedra gerardiana, and used human lung epithelial cells to demonstrate the feasibility of using the extracts as bioactive component that could enhance cell proliferation and aid in the natural cure for lung related disorders.

\section{Materials and Methods}

2.1. Chemicals. Gelatin (from porcine skin, $M W \sim 60,000$ ), glutaraldehyde (25\% v/v), Dulbecco's modified Eagle's medium (DMEM), fetal bovine serum (FBS), penicillin, streptomycin, (4,5-dimethylthiazol-2-yl)-2,5-diphenyltetrazolium bromide (MTT), phosphate buffer saline (PBS), and dimethyl sulfoxide (DMSO) were purchased from Sigma Aldrich (St. Louis, MO, USA). Live/dead staining kit life Technology was bought from Invitrogen, USA. Human lung epithelial cells (L-132) were obtained from Korean Cell Line Bank, Seoul, Republic of Korea.

2.2. Plant Material. Whole plant of Ephedra gerardiana was collected and shade-dried at room temperature. Fine powder was obtained by grinding and was used for preparation of ethyl acetate extract by Soxhlet extraction method [15]. After the completion of extraction procedure, solvent was evaporated completely using rotary evaporator, and solvent, free extract was dried by lyophilizing and stored at $4^{\circ} \mathrm{C}$ until further use.

2.3. Particle Fabrication. Gelatin particles were prepared by conventional oil-water emulsion technique. Briefly, $5 \mathrm{~g}$ of porcine gelatin was dissolved in $50 \mathrm{~mL}$ of double distilled water $\left(\mathrm{dd} \mathrm{H}_{2} \mathrm{O}\right)$ by heating it to $60^{\circ} \mathrm{C}$, and solution was added drop by drop in emulsification bath set at $15^{\circ} \mathrm{C}$ containing $250 \mathrm{~mL}$ grape seed oil with a speed of $900 \mathrm{rpm}$. Particles were allowed to form in emulsifying oil for $30 \mathrm{~min}$ and later cooled at $4^{\circ} \mathrm{C}$ in acetone $(200 \mathrm{~mL})$ for obtaining solid particles, which were then washed and filtered using surfactant and collected by centrifugation at $800 \mathrm{rpm}$. Collected particles were crosslinked with $1 \%$ glutaraldehyde for $24 \mathrm{~h}$ and were filtered and washed several times with dd $\mathrm{H}_{2} \mathrm{O}$ to remove traces of non-cross-linked glutaraldehyde and polymers. Particles were finally lyophilized in order to remove all the traces of oil and acetone and stored until further use [16].
2.4. Particle Size and Morphology. Morphology of microparticle was examined using scanning electron microscopy (FEI Quanta 200). Microparticles were dried overnight to remove any trace of moisture before platinum coating was done using a sputter coater (Hitachi E-1030). The microscope was operated under standard condition (high vacuum at $15 \mathrm{kV}$ ) and spot size of $4.5 \mathrm{~mm}$ for imaging the samples.

The size distribution of fabricated microparticles was examined to determine the size with a laser scattering instrument (Nano-ZS, Malvern Instruments, UK) which is suitable for particle sizes ranging from $0.3 \mathrm{~nm}$ to $10 \mu \mathrm{m}$. The particle size distribution was measured by dynamic light scattering with the angle of $173^{\circ}$. The measurements made in this work are reported as the particle size distribution. The size of gelatin particle of $0.5 \mathrm{wt} \%$ was dispersed in $2 \mathrm{~mL}$ grape seed oil. Samples were analyzed in triplicate, and average mean value is reported as particle size.

2.5. Water Uptake by Particles. Water absorbing capacity of the particles was examined by observing the amount of water absorbed by dry particles at $37^{\circ} \mathrm{C}$. Briefly, dry weight of particles was noted $\left(W_{d}\right)$ before immersing the sample in $1 \mathrm{~mL}$ of water. Initial dry weight followed by wet weight of particles was recorded, and water uptake capacity was calculated using the following equation:

$$
\text { Water content }(\%)=\frac{W_{s}-W_{d}}{W_{d}} \times 100 \text {. }
$$

In this equation $W_{s}$ and $W_{d}$ are the weights of hydrated (wet) and dry particles, respectively. The experiment was repeated 5 times to obtain the concurrent value.

2.6. Microparticles with Ephedra Extracts. Water uptake ability of particles was used to load solvent-free extract of $E$. gerardiana. Gelatin microparticles $(100 \mathrm{mg})$ were loaded with $1 \mathrm{mg} / \mathrm{mL}$ concentration ( $\mathrm{w} / \mathrm{v}$ in PBS) of solvent-free extract and incubated overnight at $37^{\circ} \mathrm{C}$ for particles to get saturated with the extract. After overnight incubation, particles were washed quickly with PBS to remove any unbound phytochemicals on the surface and then lyophilized [16].

2.7. Drug Release Profile Studies of Microparticle. Drug release profile was performed by recording the absorbance of phytochemicals released from the microparticles using UV (UV2600, shimadzu) spectrophotometer at spectrum ranging from 200 to $700 \mathrm{~nm}$. Phosphate buffer saline (PBS, pH 7.4) was used as a release medium. Particles loaded with Ephedra extract were suspended in $10 \mathrm{~mL}$ of PBS, and the system was incubated at $37^{\circ} \mathrm{C}$ with continuous stirring. PBS $(0.5 \mathrm{~mL})$ was taken out and scanned under spectrophotometer at specific intervals ( $2 \mathrm{hr}$ and $8 \mathrm{hr}$ and $1,2,3,4,5,6$, and 7 days). Fresh PBS was added after removing $0.5 \mathrm{~mL}$ for release study. All experiments were set up in triplicate for concurrent readings.

2.8. In Vitro Cell Proliferation. Particles as control (without extract) and those loaded with Ephedra extract were seeded with human lung epithelial cells (L-132) with cell seeding 


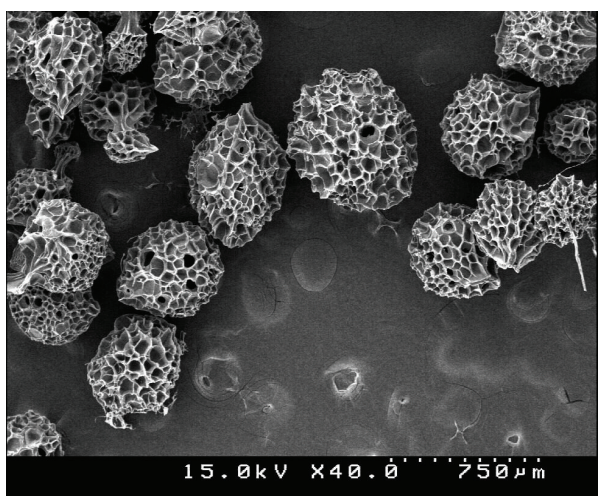

(a)

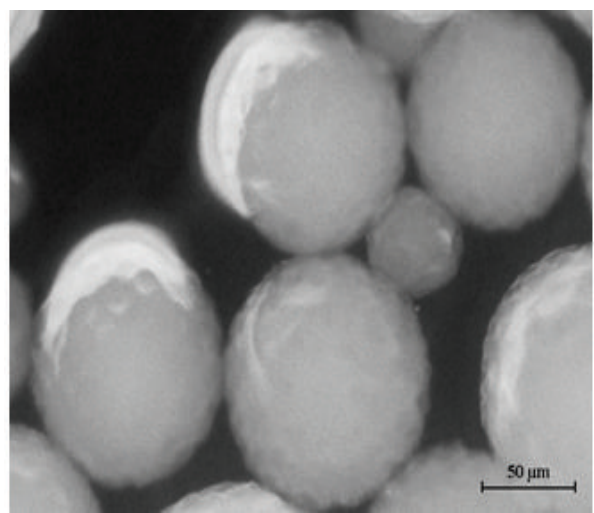

(c)

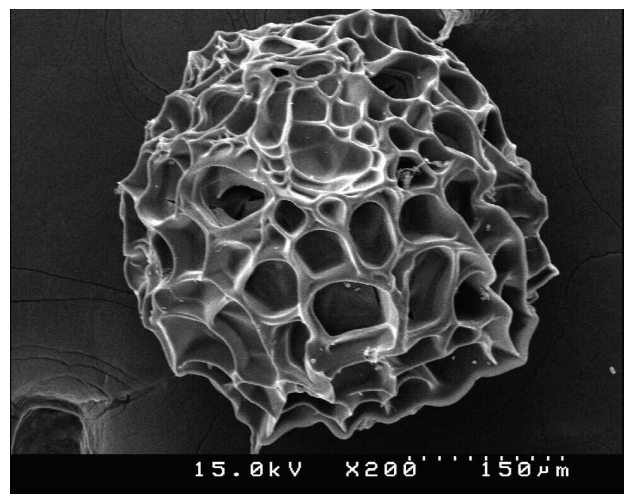

(b)

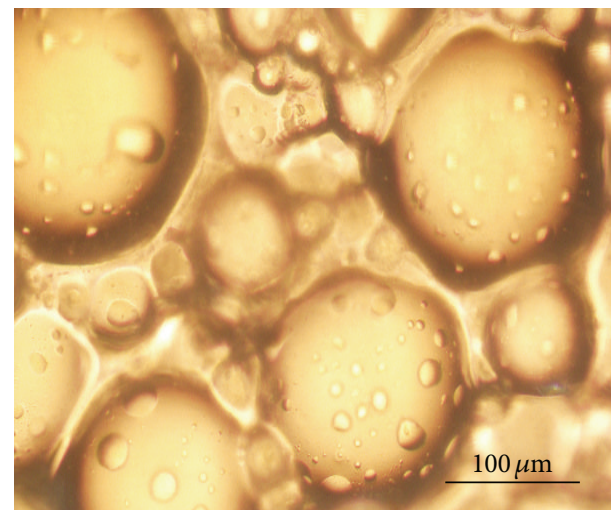

(d)

FIGURE 1: Scanning electron microscopy images of cross-linked gelatin particles showing porous morphology at lower (a) and higher magnification (b). The bright field microscopy images of cross-linked particle (c) and non-cross-linked gelatin microparticles (d).

density of $1 \times 10^{5}$ cells $/ \mathrm{mL}$. Cells were allowed to interact and settle on particles before complete DMEM (with 10\% FBS, $1 \%$ penicillin/streptomycin) was added in each well and plates were incubated at $37^{\circ} \mathrm{C}$ with $5 \% \mathrm{CO}_{2}$. SEM analysis was performed to determine the attachment of cells on particles, for which particles were gently washed with $0.01 \mathrm{M} \mathrm{PBS}(\mathrm{pH}$ 7.46) twice before fixing with $2.5 \%$ glutaraldehyde for scanning electron microscopy examination (FEI Quanta 200).

\subsection{Biocompatibility Testing of E. gerardiana Loaded on} Gelatin Particle. 3-(4,5-Dimethylthiazol-2-yl)-2,5-diphenyltetrazolium bromide (MTT) assay was performed every $24 \mathrm{~h}$ to evaluate the total metabolic activity of cells proliferating on particles. Experiment was set up in triplicate for 11 days. Briefly, media were discarded from test and control wells followed by gently washing the wells with $0.01 \mathrm{M}$ PBS. The working solution of MTT $(0.5 \%)$ was added to each well $(500 \mu \mathrm{L})$ followed by incubation at $37^{\circ} \mathrm{C}$ for $3 \mathrm{~h}$. After $3 \mathrm{~h}$ of incubation, dimethyl sulfoxide (DMSO) was added after discarding MTT solution carefully at a ratio 1:3 to each test well. Adding DMSO results in dissolution of intracellular formazan crystals thereby developing a blue-violet color end product measuring $490 \mathrm{~nm}$ using spectrophotometer (Shimadzu UV-2600) [17].
2.10. Imaging of Cells on Particles. Cell seeded particles were viewed using fluorescent microscopy to check for cellular proliferation and attachment of cells to the particles. Working solution of live/dead staining was prepared by diluting ethidium bromide stock ( $2 \mathrm{mM}$ ) in $10 \mathrm{~mL}$ distilled PBS (tissue culture grade) along with $4 \mu \mathrm{m}$ of calcein AM. $200 \mu \mathrm{L}$ of the working solution was added to the test well, and plates were incubated for $45 \mathrm{~min}$ at room temperature, and stained cells were observed under Nikon fluorescent microscope [18].

\section{Results}

3.1. Particle Size and Morphology. Gelatin particles prepared by oil-water emulsification technique were cross-linked using glutaraldehyde after fabrication to stabilize the structure (Figures 1(b)-1(c)). Cross-linking of particles using glutaraldehyde was performed under constant stirring and temperature to stabilize the shape and size (Figures $1(\mathrm{a})-1(\mathrm{~d})$ ). $10 \%$ gelatin concentration and precipitation of particles with acetone at constant speed resulted in formation of gradient of particles. The smallest nanoparticles were floating upon centrifugation, and large micro- and macro-particles formed sediment at the bottom of the tube. No aggregation of the particles was observed during cross-linking when performed under 


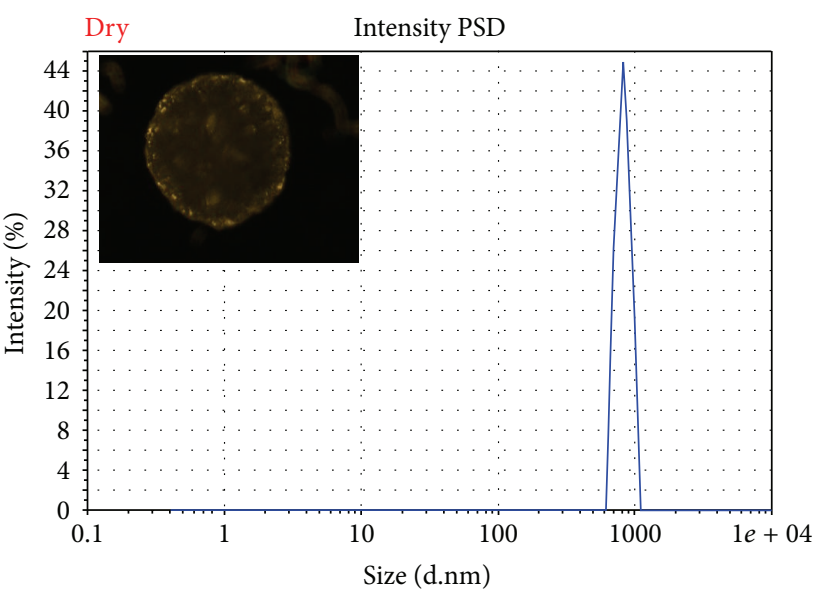

(a)

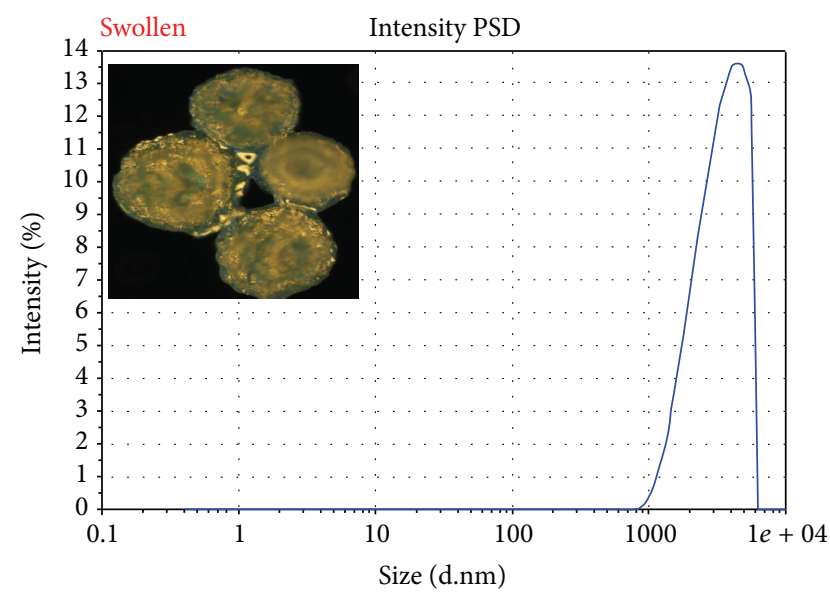

(b)

FIGURE 2: Size distribution of the microparticle was performed using zeta potential system, and diameter distribution profile of gelatin microparticles was found to be in range of $600 \mathrm{~nm}$ (dry) $\sim 3.4 \mu \mathrm{m}$ (swollen).

TABLE 1: Details of different conditions and their effect on gelatin particles.

\begin{tabular}{|c|c|c|c|}
\hline Conditions & Optimized conditions & Above the optimized conditions & Below the optimized conditions \\
\hline Gelatin concentration & $10 \pm 0.1 \mathrm{wt} \%$ & Random size & Unstable \\
\hline Glutraldehyde (Cross-linker) concentration & $1 \pm 0.25 \mathrm{wt} \%$ & Aggregate & Disintegrated \\
\hline Cross-linking time & $24 \pm 0.30 \mathrm{~h}$ & Stiff and brittle & Too soft \\
\hline Speed & $900 \pm 0.25 \mathrm{rpm}$ & Not formed & Forms rods \\
\hline
\end{tabular}

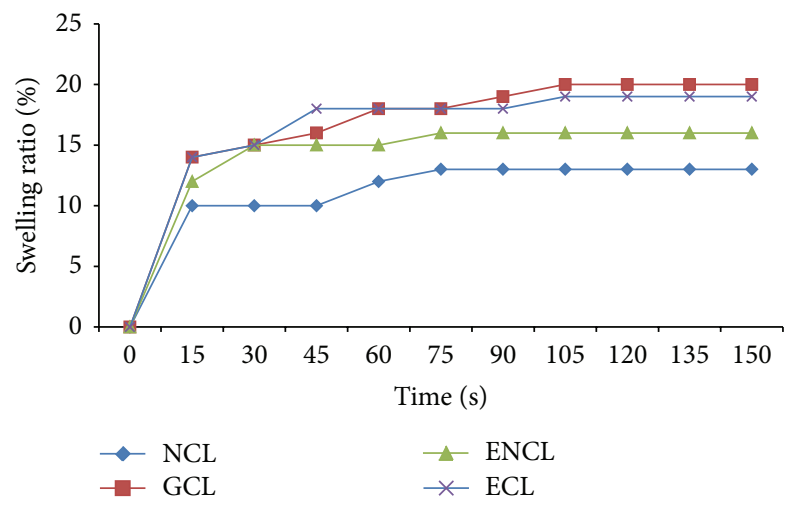

FIGURE 3: Swelling kinetics of microparticles performed to check for the variation in water uptake capacity of non-cross-linked (NCL), glutaraldehyde cross-linked (GCl), Ephedra loaded cross-linked $(\mathrm{ECl})$, and Ephedra loaded non-cross-linked (ENCL) particles.

constant stirring. The average diameter of the particle was found in the range from $600 \pm(0.23) \mathrm{nm}$ to $1.5 \pm 0.12 \mu \mathrm{m}$.

Diameter distribution of the gelatin microparticles of $0.5 \mathrm{wt} \%$ dispersed in $2 \mathrm{~mL}$ grape seed oil was measured by a laser scattering instrument (Figure 2). These fabricated gelatin microparticles were found to have an average diameter of $824 \mathrm{~nm}$ in dry state and about $3.4 \mu \mathrm{m}$ in swollen state with the distribution ranging from $600 \mathrm{~nm}$ to $1.32 \mu \mathrm{m}$.
3.2. Swelling Kinetics of the Particles. The swelling kinetics performed showed quick water uptake capacity by these microparticles as they reached equilibrium within $400 \mathrm{sec}$ (Figure 3). The water uptake capacity of the microparticle was affected with the cross-linking as the non-cross-linked microparticle showed lower water absorption capacity when compared to cross-linked and microparticle loaded with plant extracts. Gelatin particle was fabricated, and $1 \%$ crosslinking with time duration of $24 \mathrm{~h}$ resulted in stable structure of microparticles with the highest water uptake capacity indicating the relationship between the cross-linking agent and the time required for the microparticle to reach equilibrium state (Table 1). This is important property while loading the drug onto microparticle as these drugs were water soluble and mostly entrapped into the delivery vehicle.

3.3. Drug Release and Cell Compatibility Profile. The rate of drug release from cross-linked microparticle was examined by quantification of the amount taken up by the particle over the period of incubation. No burst release from the particle was observed (Figure 4(a)) by spectrophotometric study, and over the period of 6 days, sustainable release of the extract from microparticles was observed. Spectrum obtained on each day shows the release of phytocompounds, indicating the presence of alkaloids, phenols usually detected under UV range (Figure $4(\mathrm{~b})$ ). 


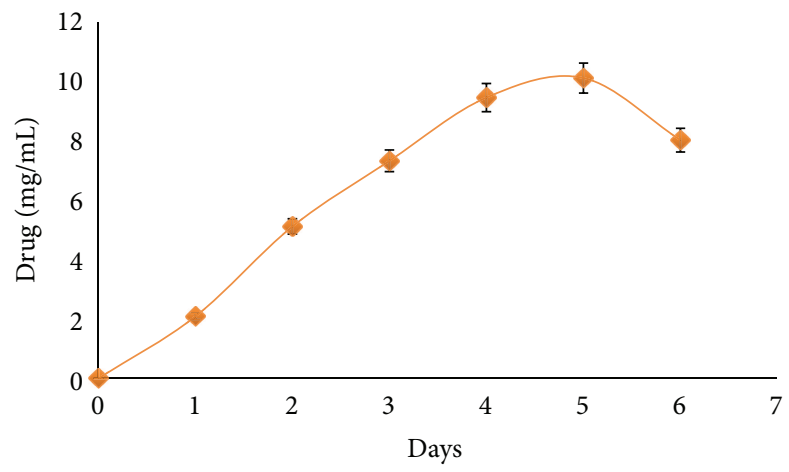

Particle loaded with drug

(a)
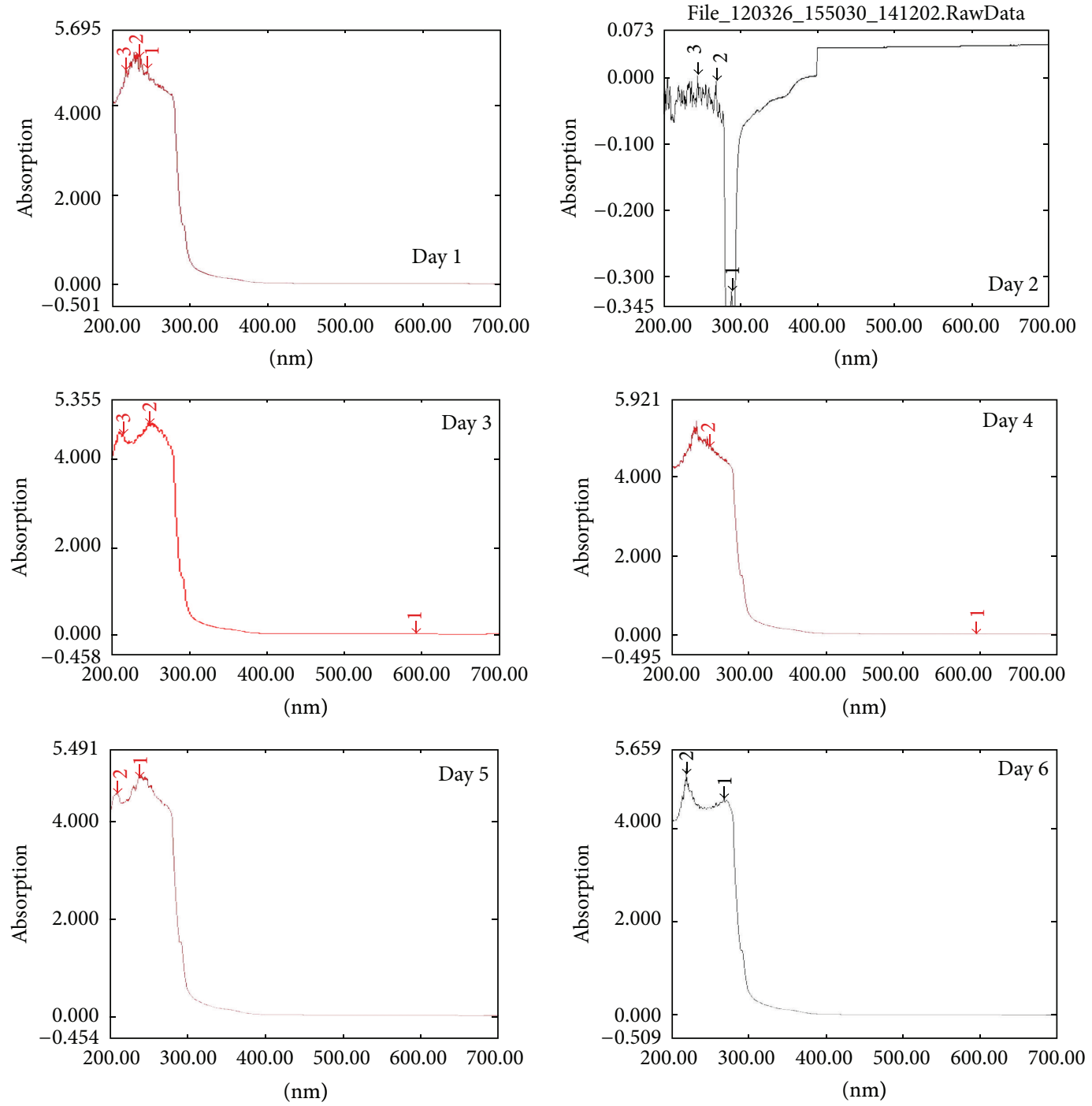

(b)

Figure 4: Cumulative release profile of Ephedra gerardiana extract loaded onto gelatin microparticle (a). The spectrum obtained on each day shows the release of phytocompounds, indicating the presence of alkaloids, phenols usually detected under UV range (b). 


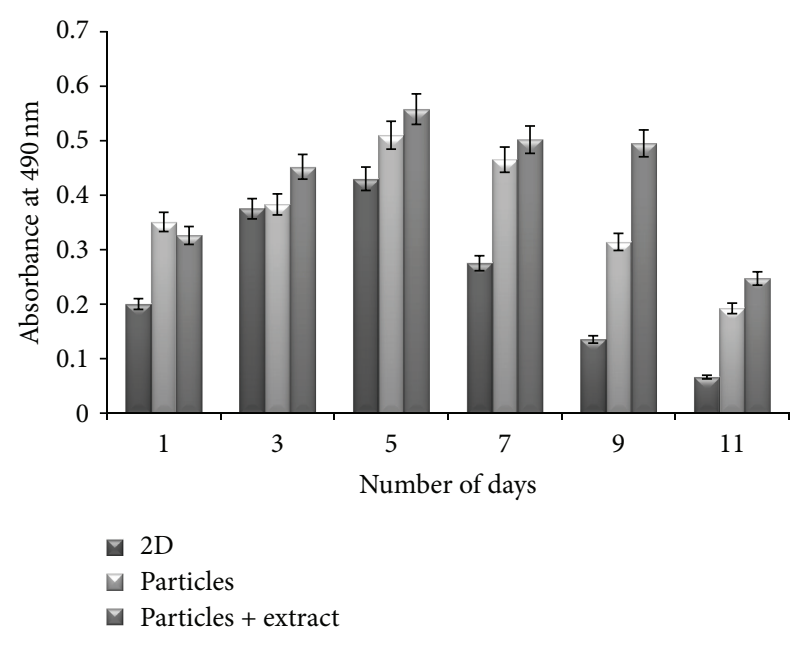

FIGURE 5: Lung cell proliferation rate analyzed by MTT on gelatin microparticles loaded with herbal extract in comparison with particle and 2D system.

3.4. MTT Assay. MTT assay performed to check the cytotoxic activity of extracts loaded particles showed the cytoprotective ability of phytochemicals present in Ephedra extract. Over the period of 2 weeks, gelatin microparticles and particles loaded with solvent-free extract showed higher proliferation of lung cells in comparison to control (2D) without extract. From the 5th day decrease metabolic activity was observed in $2 \mathrm{D}$ whereas lung epithelial cells cultured on microparticles with and without extracts showed constant increasing trend and cells were metabolically more active. However, the metabolic activity reduced over a period of two weeks in microparticles without extracts, whereas extract loaded particles were found to support and enhance the activities of cells (Figure 5).

3.5. SEM and Imaging Analysis of Cell Growth on Microparticles. SEM images of cells cultured on particles (with/without extracts) on day 1 and day 9 show cell attachment, proliferation, and ECM production over the porous particles. Cells were seen attached on surface and pore of the particles with higher ECM production on particles loaded with Ephedra extract than on control particles (without extracts) (Figure 6).

Live/dead viability assay performed on the mid-time interval, that is, on day 7 , showed the presence of greater number of cells stained green indicating viable, live cells attached on gelatin microparticles with and without extract (Figure 7). The presence of higher number of viable cells cultured on gelatin microparticle shows the biocompatible nature of the particle; however, the higher metabolically active cells in the presence of the plant extracts show the efficacy of these extracts as bioactive components.

\section{Discussion}

The main aim of regenerative medicine is to enhance the healing process of injured tissue or organ using different approaches like stem cells delivery to local site or using threedimensional scaffolds loaded with cells for in vivo regeneration. The central dogma is to aid the healing process without eliciting any immune response. Lung related diseases account for 400,000 deaths in USA alone annually, and this can be attributed to the fact that lungs have restricted self-healing rate, and once damaged, the regeneration beyond microscopic level is virtually impossible. Different approaches have been employed to overcome this limitation including decellularization of the lung tissue and re-implanting with progenitor cells. Artificial polymeric scaffold is now explored to regenerate small portion of tissue lost due to emphysema [19-21]; however, since the lung is one of the most complex, dynamic and vascularized organs has limited success so far. The alternative of this could be the identification of a bioactive compound that enhances the cell regenerating capacity. In step towards this, various natural and synthetic compounds have been screened and tested which could either enhance healing process or prevent further deterioration of the tissue due to microbial infection. Traditional Chinese and Indian medicine reports the use of E. gerardiana in various ailments like asthma, cold, nasal blocks/congestion, hay fever, wheezing, and fever due to various other infections [22]. The plant is reported to contain ephedrine as a major alkaloid, which acts as a decongesting agent along with decreasing hypertension and acting at cellular level. Individual and combined effects of ephedrine and pseudoephedrine were tested for cytotoxic effect on neuroblastoma and myoblast cells lines and cellviability were observed to be dose dependent. With the increase in concentration, the decrease in cell viability was reported [23, 24]. Our study reports the sustained release of extract which ensures longer availability at the healing site which is one of the desired criteria in curing any ailment without causing any cytotoxicity to the proliferating cells. The entire plant or its specific alkaloids like ephedrine are effective bronchodilators which along with theophylline can be prescribed in appropriate dose with no side effects, toxicity, or long-term tolerance development [10].

Gelatin has been extensively used by many researchers as a natural biomaterial in the field of tissue engineering [9, $21,25,26]$. In this study glutaraldehyde cross-linked gelatin microparticles were used for in vitro proliferation of lung cells loaded with solvent-free extract of Ephedra. To obtain stable, porous, uniform sized particles, various parameters like time, speed, temperature, and polymer concentration were optimized as they play critical role during fabrication procedure. Concentration of polymer played impetus role in determining the size of particles. With higher polymer concentration, solution was viscous and hence difficult for uniform droplet formation; moreover, the speed of oil-gelatin slurry mixing too had an effect upon the particle size. High speed leads to particles breaking and nonuniform size, which results in low yield. Removal of solvent and temperature is again one of the critical steps as it changes the surface morphology of the particles. Rapid solvent evaporation at room or higher temperature leads to the formation of porous particles [27] which was the desired parameter in our study. Generally postfabrication and cross-linking microparticles tend to aggregate resulting in major hindrance [25]. 

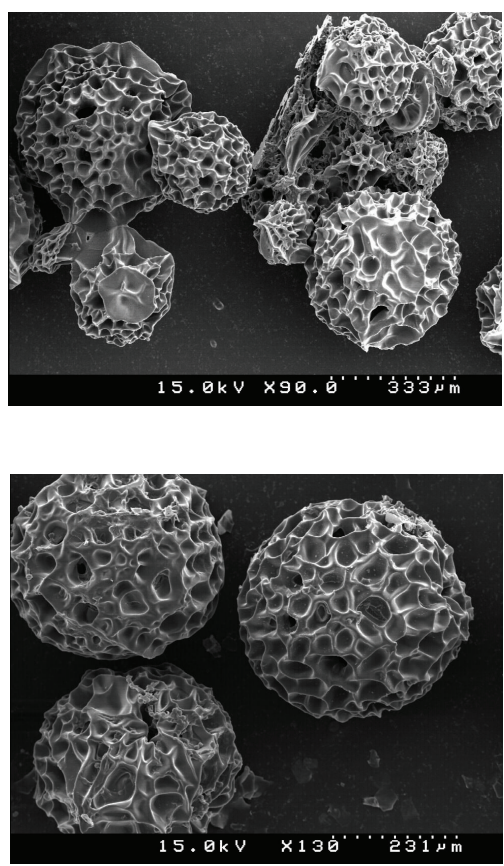

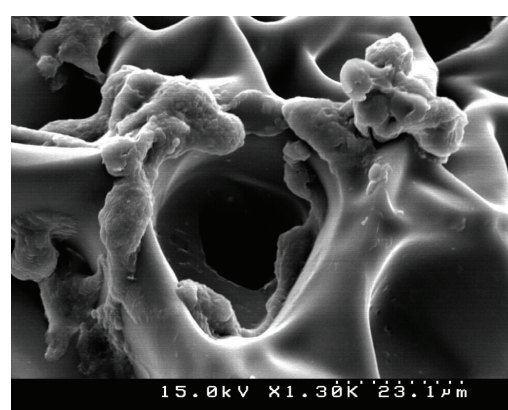

(a)

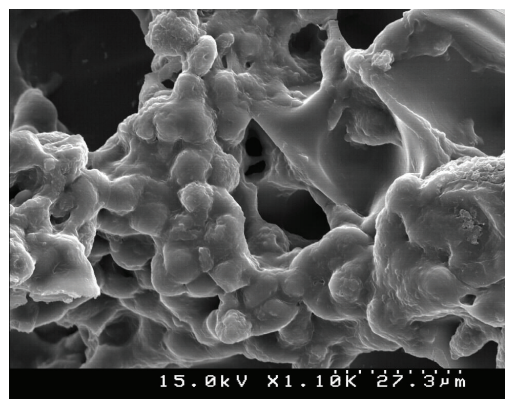

(b)
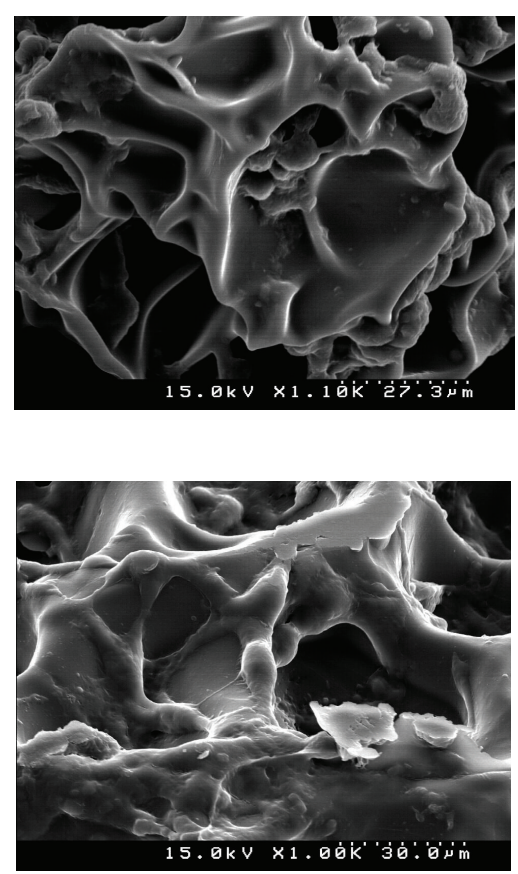

FIGURE 6: Scanning electron micrographs of gelatin microparticle (a) and particles loaded with Ephedra gerardiana (b) seeded with lung cells. Particles with Ephedra gerardiana extract showed higher cellular attachment and proliferation in comparison with cells on gelatin microparticles alone.

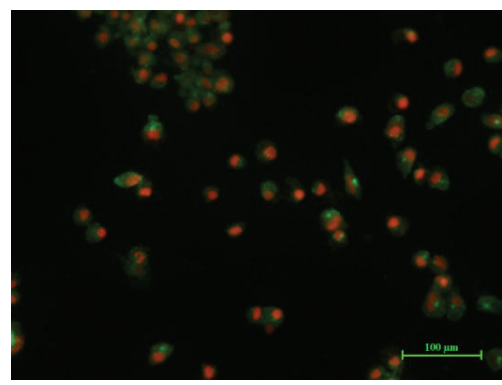

(a)

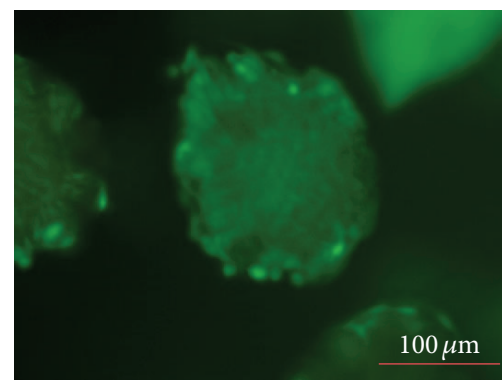

(b)

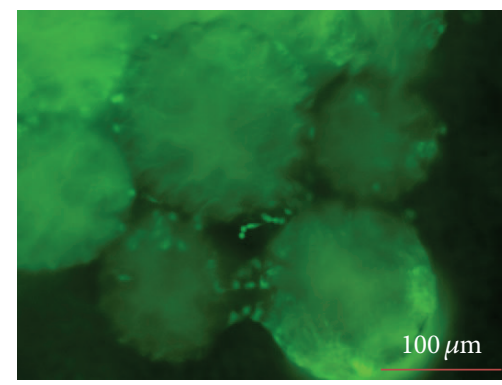

(c)

FIGURE 7: Live/dead staining of cells cultured on gelatin microparticles (b) loaded with herbal drug (c) and 2D (a).

Microparticles or scaffold based on polymers mostly have hydrophilic backbone and are cross-linked using suitable cross-linkers. These chemical chains along with physical forces determine the water uptake capacity of the gel or particles, and altering the chemical composition or the crosslinking agent can modulate the swelling kinetics of the particles. As reported earlier by Vandelli et al., concentration and time during cross-linking alter the mobility of macromolecular chains of gelatin; similar results were observed in this study, and $1 \%$ cross-linking with time duration of $24 \mathrm{~h}$ resulted in stable structure of microparticles with highest water uptake capacity.

In this study we have explored the efficacy of the herbal drug as possible bioactive component along with designing carrier for drug delivery to local injured area of lung as the cell proliferation was significantly higher in particles. $E$. gerardiana extract, which enhanced the lung cell proliferation and maintained the viability, could be explored for treatment of lung related diseases.

\section{Conclusion}

Gelatin-based microparticles could be the simplest delivery vehicle for Ephedra gerardiana as the release was found to be controlled, and significant amount of the phytochemicals was released over one-week time, and rate of extract release was in accordance with the cellular proliferation profile indicating that the components from the plants could play a significant role in the higher cellular metabolic rate and can be explored as potential drug for lung related ailments. 


\section{Authors' Contribution}

Dolly Singh and Deepti Singh have contributed equally to this paper.

\section{Acknowledgment}

This work was supported by 2013 Yeungnam University Research Grant.

\section{References}

[1] N. Adhirajan, N. Shanmugasundaram, and M. Babu, "Gelatin microspheres cross-linked with EDC as a drug delivery system for doxycyline: development and characterization," Journal of Microencapsulation, vol. 24, no. 7, pp. 659-671, 2007.

[2] D. M. G. Cruz, J. L. E. Ivirico, M. Gomes et al., "Chitosan microparticles as injectable scaffolds for tissue engineering," Journal of Tissue Engineering and Regenerative Medicine, vol. 2, no. 6, pp. 378-380, 2008.

[3] W. J. E. M. Habraken, O. C. Boerman, J. G. C. Wolke, A. G. Mikos, and J. A. Jansen, "In vitro growth factor release from injectable calcium phosphate cements containing gelatin microspheres," Journal of Biomedical Materials Research A, vol. 91, no. 2, pp. 614-622, 2009.

[4] A. P. McGuigan and M. V. Sefton, "Modular tissue engineering: fabrication of a gelatin-based construct," Journal of Tissue Engineering and Regenerative Medicine, vol. 1, no. 2, pp. 136-145, 2007.

[5] G. A. Silva, P. Ducheyne, and R. L. Reis, "Materials in particulate form for tissue engineering. 1. Basic concepts," Journal of Tissue Engineering and Regenerative Medicine, vol. 1, no. 1, pp. 4-24, 2007.

[6] M. Yamamoto, Y. Ikada, and Y. Tabata, "Controlled release of growth factors based on biodegradation of gelatin hydrogel," Journal of Biomaterials Science, Polymer Edition, vol. 12, no. 1, pp. 77-88, 2001.

[7] S. Young, M. Wong, Y. Tabata, and A. G. Mikos, "Gelatin as a delivery vehicle for the controlled release of bioactive molecules," Journal of Controlled Release, vol. 109, no. 1-3, pp. 256-274, 2005.

[8] S. K. Sahoo, A. K. Panda, and V. Labhasetwar, "Characterization of porous PLGA/PLA microparticles as a scaffold for three dimensional growth of breast cancer cells," Biomacromolecules, vol. 6, no. 2, pp. 1132-1139, 2005.

[9] Z. S. Patel, M. Yamamoto, H. Ueda, Y. Tabata, and A. G. Mikos, "Biodegradable gelatin microparticles as delivery systems for the controlled release of bone morphogenetic protein-2," Acta Biomaterialia, vol. 4, no. 5, pp. 1126-1138, 2008.

[10] V. Sharma, S. K. Gupta, and M. Dhiman, "Regeneration of plants from nodal and internodal segment cultures of Ephedra gerardiana using thidiazuron," Plant Tissue Culture and Biotechnology, vol. 22, no. 2, pp. 153-161, 2012.

[11] R. Mahadeva and S. D. Shapiro, "Chronic obstructive pulmonary disease $\cdot 3$ : experimental animal models of pulmonary emphysema," Thorax, vol. 57, no. 10, pp. 908-914, 2002.

[12] T. H. March, F. H. Y. Green, F. F. Hahn, and K. J. Nikula, "Animal models of emphysema and their relevance to studies of particleinduced disease," Inhalation Toxicology, vol. 12, no. 4, pp. 155187,2000
[13] K. Kawai, S. Suzuki, Y. Tabata, Y. Ikada, and Y. Nishimura, "Accelerated tissue regeneration through incorporation of basic fibroblast growth factor-impregnated gelatin microspheres into artificial dermis," Biomaterials, vol. 21, no. 5, pp. 489-499, 2000.

[14] http://www.psr.org/resources/coals-assault-on-human-health .html.

[15] D. Singh, N. Chauhan, S. S. Sawhney, and R. M. Painuli, "Biochemical characterization of triphala extracts for developing potential herbal drug formulation for ocular diseases," International Journal of Pharmacy and Pharmaceutical Sciences, vol. 3, no. 5, pp. 516-523, 2011.

[16] M. A. Vandelli, F. Rivasi, P. Guerra, F. Forni, and R. Arletti, "Gelatin microspheres crosslinked with D,L-glyceraldehyde as a potential drug delivery system: preparation, characterisation, in vitro and in vivo studies," International Journal of Pharmaceutics, vol. 215, no. 1-2, pp. 175-184, 2001.

[17] D. Singh, V. Nayak, and A. Kumar, "Proliferation of myoblast skeletal cells on three-dimensional supermacroporous cryogels," International Journal of Biological Sciences, vol. 6, no. 4, pp. 371-381, 2010.

[18] S. M. Zo, D. Singh, A. Kumar, Y. W. Cho, T. H. Oh, and S. S. Han, "Chitosan-hydroxyapatite macroporous matrix for bone tissue engineering," Current Science, vol. 103, no. 12, pp. 14381446, 2012.

[19] M. K. Lee, B. W. H. Cheng, C. T. Che, and D. P. H. Hsieh, "Cytotoxicity assessment of ma-huang (Ephedra) under different conditions of preparation," Toxicological Sciences, vol. 56, no. 2, pp. 424-430, 2000.

[20] D. Singh, S. M. Zo, A. Kumar, and S. S. Han, "Engineering three-dimensional macroporous hydroxyethyl methacrylatealginate-gelatin cryogel for growth and proliferation of lung epithelial cells," Journal of Biomaterial Sciences Polymer, vol. 24, no. 11, pp. 1343-1359, 2013.

[21] J. Basu, C. W. Genheimer, E. A. Rivera et al., "Functional evaluation of primary renal cell/biomaterial neo-kidney augment prototypes for renal tissue engineering," Cell Transplantation, vol. 20, no. 11-12, pp. 1771-1790, 2011.

[22] A. Y. Leung and S. Foster, "Encyclopedia of common natural ingredients used in food, drugs and cosmetics," in Molecular Nutrition and Food Research, A. Taufel, Ed., p. 649, Wiley, New York, NY, USA, 2nd edition, 1996.

[23] Y. Gong, Z. Ma, Q. Zhou, J. Li, C. Gao, and J. Shen, "Poly(lactic acid) scaffold fabricated by gelatin particle leaching has good biocompatibility for chondrogenesis," Journal of Biomaterials Science, Polymer Edition, vol. 19, no. 2, pp. 207-221, 2008.

[24] Y. Choi, J.-R. Joo, A. Hong, and J.-S. Park, "Development of drug-loaded PLGA microparticles with different release patterns for prolonged drug delivery," Bulletin of the Korean Chemical Society, vol. 32, no. 3, pp. 867-872, 2011.

[25] L. G. Griffith, "Polymeric biomaterials," Acta Materialia, vol. 48, no. 1, pp. 263-277, 2000.

[26] W. L. Lee, Y. C. Seh, E. Widjaja, H. C. Chong, N. S. Tan, and S. C. J. Loo, "Fabrication and drug release study of double-layered microparticles of various sizes," Journal of Pharmaceutical Sciences, vol. 101, no. 8, pp. 2787-2797, 2012.

[27] T. A. Holland, Y. Tabata, and A. G. Mikos, "In vitro release of transforming growth factor- $\beta 1$ from gelatin microparticles encapsulated in biodegradable, injectable oligo(poly(ethylene glycol) fumarate) hydrogels," Journal of Controlled Release, vol. 91, no. 3, pp. 299-313, 2003. 

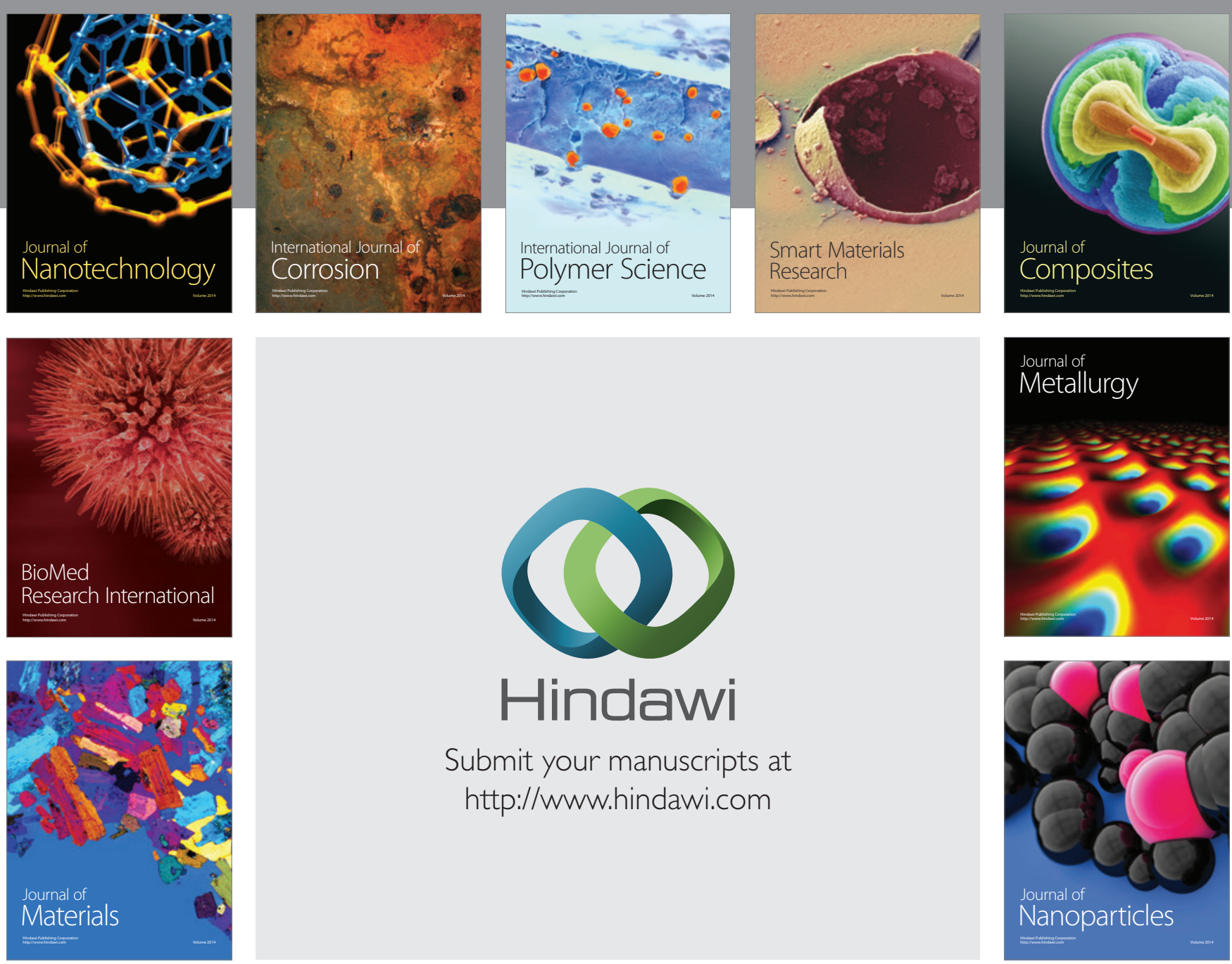

Submit your manuscripts at http://www.hindawi.com
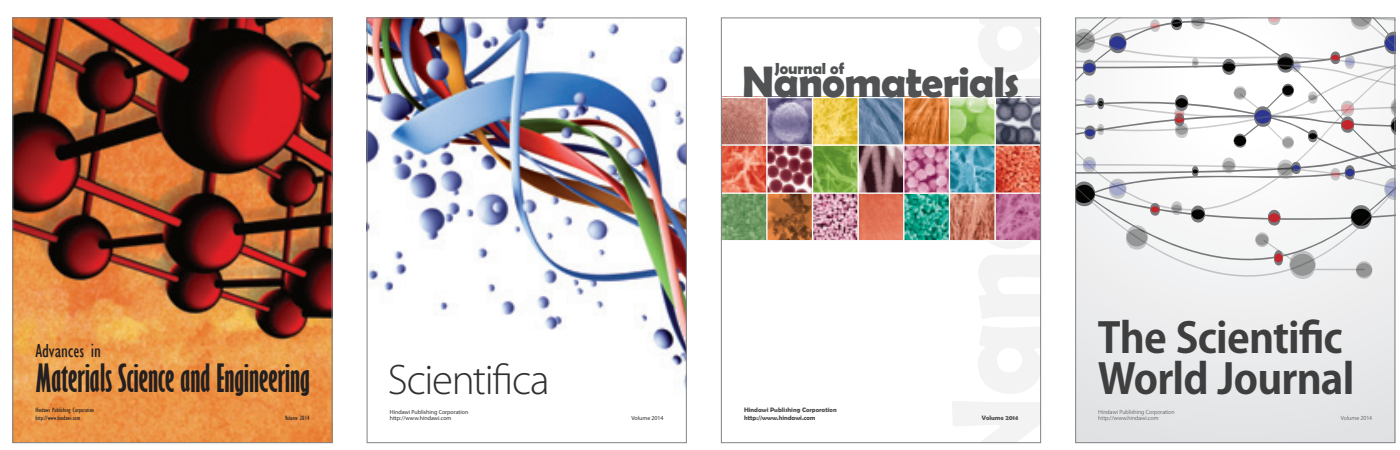

\section{The Scientific World Journal}
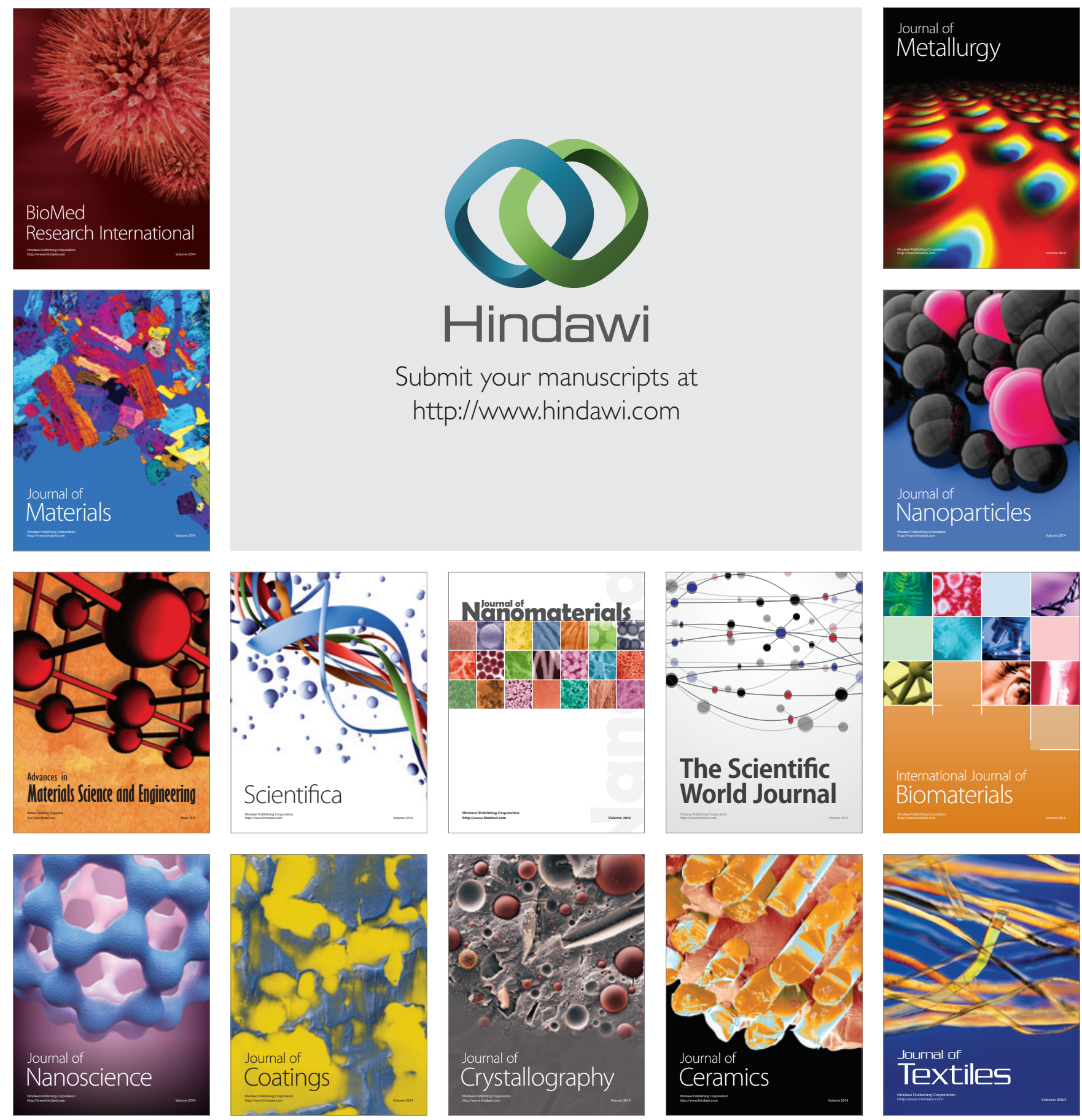